\title{
Inactivation of a sperm motility gene by insertion of an epidermal growth factor receptor transgene whose product is overexpressed and compartmentalized during spermatogenesis
}

\author{
Glenn T. Merlino, ${ }^{1,2}$ Cheryl Stahle, ${ }^{1}$ Chamelli Jhappan, ${ }^{1}$ Robert Linton, ${ }^{1}$ Kathleen A. Mahon, ${ }^{3}$ \\ and Mark C. Willingham ${ }^{1}$ \\ ${ }^{1}$ Laboratory of Molecular Biology, Division of Cancer Biology, Diagnosis, and Centers, National Cancer Institute, and \\ ${ }^{3}$ Laboratory of Mammalian Genes and Development, National Institute of Child Health and Human Development, National \\ Institutes of Health, Bethesda, Maryland 20892 USA
}

Transgenic mice were generated with a human epidermal growth factor (EGF) receptor cDNA driven by the chicken $\beta$-actin gene promoter. One line (AE24) that exhibited a unique expression pattern in which dramatically elevated levels of EGF receptor RNA were found only in the testis was established, suggesting that the $\beta$-actin promoter was being influenced by an adjacent testis-specific enhancer. EGF receptor RNA was detected in primary spermatocytes, whereas the synthesis of receptor protein was restricted to elongate spermatids, indicating that transgene expression was under translational control. At spermiation, the EGF receptor was sequestered in residual bodies and excluded from mature sperm by a compartmentalization mechanism. About half of AE24 homozygous males were sterile because of sperm paralysis, whereas heterozygous males and females of either genotype were completely fertile. Electron microscopic analysis of sperm flagella from sterile AE24 homozygotes revealed an aberrant axonemal structure in which outer doublet microtubules were missing from the middle piece, resembling changes observed in the sperm of some infertile humans. Flagellar axonemal disassembly was observed in the vas deferens and epididymis but not in the testis, suggesting that outer doublets were assembled in a grossly normal manner but possessed a latent instability. These results demonstrate that in the AE24 mouse line the EGF receptor transgene was integrated into and inactivated an endogenous autosomal gene, causing sperm flagellar axonemal disruption and male sterility.

[Key Words: Flagellar microtubule; recessive mutation; sterility; testis; transgenic; translational control]

Received April 11, 1991; revised version accepted June 3, 1991.

Mammalian spermatogenesis consists of a complex series of biochemical and morphological alterations culminating in the generation of mature haploid spermatozoa (Hecht 1986; Handel 1987). The spermatogenic process can be subdivided into three main phases: mitotic renewal of germ-cell spermatogonia, meiotic reduction division of spermatocytes, and differentiation of spermatids into spermatozoa during spermiogenesis. Some understanding of these events has come from a genetic analysis of heritable defects in fertility. However, in mice, virtually every spontaneous mutation associated with male sterility that has been described also causes pleiotropic pathologic effects (for reviews, see Handel 1987; Green 1989|. These mutations are usually identi-

${ }^{2}$ Corresponding author. fied by phenotypes unrelated to reproductive capabilities, and mutations affecting only male fertility are rarely detected. The expression of these other pathologic phenotypes makes the determination of the specific effect of a given gene on sperm structure and/or function problematic.

The ability to generate and study genetic mutations in mice has been greatly enhanced by the advent of transgenic technology. Although most transgenic mice created by the microinjection of DNA into one-cell mouse embryos have been used to explore the dominant effects of transgene expression, much information has also been gleaned from the study of insertional mutations resulting from random transgene integration (e.g., see Costantini et al. 1989; Shawlot et al. 1989; Woychik et al. 1990; Xiang et al. 1990), including mutations associated with 
spermatogenesis and male sterility (Krulewski et al. 1989; Gordon et al. 1990; MacGregor et al. 1990).

Here we report the creation of a transgenic mouse line with a sterile male recessive mutant phenotype resulting from the integration of an epidermal growth factor (EGF) receptor fusion gene. The EGF receptor mediates the mitogenic potential of specific growth factors, including EGF and transforming growth factor $\alpha$ (TGF $\alpha)$, and triggers a cascade of biochemical events leading to cellular proliferation (for a review, see Merlino 1990). To determine the consequences of overexpression of the EGF receptor in a wide range of tissue types, we generated transgenic mice in which the expression of a human EGF receptor cDNA was driven by the chicken $\beta$-actin gene promoter.

In one line of these transgenic mice (AE24), an extremely high level of the EGF receptor was detected predominantly in late spermatids of the testis. Furthermore, the expression of the EGF receptor transgene was translationally regulated. The creation of homozygous AE24 mice uncovered an insertional mutation in an endogenous gene causing sperm paralysis and male sterility but no other abnormal phenotypes. This communication describes the characterization of this transgenic mouse line and its mutant phenotype.

\section{Results}

\section{Generation of EGF receptor transgenic mice}

An EGF receptor expression vector consisting of $0.34 \mathrm{kbp}$ of the chicken $\beta$-actin promoter, $4.06 \mathrm{kbp}$ of the human EGF receptor CDNA, and a $0.4-\mathrm{kbp}$ polyadenylation signal from the Abelson murine leukemia virus (MuLV) long terminal repeat (LTR) was made. This expression vector was highly active when transfected into NIH-3T3 cells, as judged by immunofluorescence with a humanspecific EGF receptor monoclonal antibody /data not shown).

A 4.95-kbp PvuI-HindIII $\beta$-actin-EGF receptor fusion gene fragment (Fig. 1A) was microinjected into outbred CD1 one-cell mouse embryos. Six founder transgenic mice were generated. Two founders did not transmit the transgene through the germ line, and one founder possessed two distinct sites of transgene integration that were genetically segregated to create low-copy (AE24) and high-copy (AE24HC) transgenic mouse lines. Extensive examination of the AE24 genomic DNA revealed that a single copy of the transgene was present per haploid genome (Fig. 1C) and that the EGF receptor cDNA was structurally intact (data not shown).

\section{Unique testicular overexpression of the EGF receptor transgene}

To determine general patterns of transgene expression in $\beta$-actin-EGF receptor mice, we isolated RNAs from representative tissues obtained from the $F_{1}$ progeny of three lines of mice and analyzed them by a variety of techniques (Table 1). The results demonstrated that the lev-

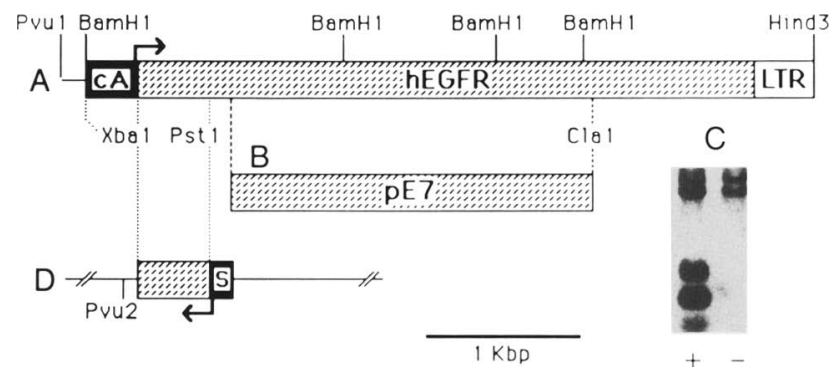

Figure 1. Transgene structure and plasmid constructs. $(A)$ The PvuI-HindIII microinjection fragment consisted of $0.34 \mathrm{kbp}$ of the chicken $\beta$-actin gene promoter $(\mathrm{cA}), 4.06 \mathrm{kbp}$ of the human EGF receptor cDNA (hEGFR), and $0.4 \mathrm{kbp}$ of the Abelson MuLV LTR containing the polyadenylation signal (LTR). The arrow indicates the start and direction of transcription. $(B)$ Insert of plasmid pE7, encoding $2.4 \mathrm{kbp}$ of the human EGF receptor cDNA, used as a hybridization probe for Southern and Northern blots. $(C)$ Southern blot analysis showing the pattern generated upon digestion of AE24 transgenic $(+)$ or nontransgenic $(-)$ mouse tail DNA with BamHI, with pE7 as a probe. (E) Endogenous mouse EGF receptor genomic fragments; $(T)$ three transgenic human EGF receptor cDNA fragments. $(D)$ Structure of plasmid pEGFR-RP, containing a 473-bp XbaI-PstI fragment from the 5' portion of the human EGF receptor cDNA inserted into pGEM3. (S) SP6 viral promoter whose transcriptional start and direction are indicated by the arrow.

els of EGF receptor RNA were dramatically elevated in the testis of line AE24 but were undetectable, low, or moderate in all other tissues examined. These results suggest that the pronounced testicular expression observed in line AE24 was unique, integration site specific, and not due solely to the presence of the chicken $\beta$-actin promoter. This conclusion was supported by expression data from two other lines of mice that bore unrelated transgenes driven by the same chicken $\beta$-actin promoter and that differed from each other and from the three EGF receptor transgenic mice (Table 1).

Northern blot hybridization was used to examine a complete panel of RNAs from the tissues of AE24 transgenic mice. Figure 2 shows that EGF receptor RNA was highly abundant only in the testis and present in very low levels in the liver $\sim \sim 25$ times lower than in the testis) and in skeletal muscle ( $\sim 60$ times lower than in the testis). The size of the EGF receptor RNA in the testis of AE24 mice was determined to be $4.4-4.5 \mathrm{~kb}$, which was larger than the predicted size of $4.1 \mathrm{~kb}$. In the high-copy line AE24HC, only a trace expression was detected in the skeletal muscle and in the testis $/ \sim 100$ times lower than in the AE24 testis).

To quantify more precisely the level of EGF receptor RNA in the AE24 testis, we used an RNase protection assay. The signal obtained from AE24 testis RNA was compared with those obtained from RNAs isolated from human KB epidermoid carcinoma cells (containing $1 \times 10^{5}$ to $2 \times 10^{5}$ EGF receptors per cell) and from human A431 epidermoid carcinoma cells (possessing $3 \times 10^{6} \mathrm{EGF}$ receptors per cell) (Xu et al. 1984). Figure 3A 
Table 1. Relative expression of transgenes in mouse tissues

\begin{tabular}{|c|c|c|c|c|c|c|c|c|c|c|c|c|c|c|}
\hline \multirow[b]{2}{*}{$\operatorname{Line}^{a}$} & \multirow[b]{2}{*}{ Gene $^{b}$} & \multirow[b]{2}{*}{ Strain } & \multicolumn{12}{|c|}{ Tissue $^{c, d}$} \\
\hline & & & $\mathrm{bm}$ & br & $\mathrm{h}$ & $\mathrm{i}$ & $\mathrm{k}$ & li & lu & $\mathrm{mu}$ & ov & $\mathrm{sp}$ & st & te \\
\hline AE6 & EGFR & $\mathrm{CD} 1$ & + & + & + & - & + & + & + & - & - & - & + & - \\
\hline AE12 & EGFR & CD1 & - & ++ & + & - & + & - & ++ & - & ++ & ++ & + & + \\
\hline AE24 & EGFR & CD1 & - & - & - & - & - & ++ & - & + & - & - & - & $\begin{array}{l}+++ \\
+++\end{array}$ \\
\hline AC5 & CAT & CD1 & - & - & +++ & - & - & + & + & - & ++ & - & + & ++ \\
\hline $\mathrm{AM} 39^{\mathrm{e}}$ & MDR & C57 & +++ & - & - & - & - & - & - & + & + & +++ & - & - \\
\hline
\end{tabular}

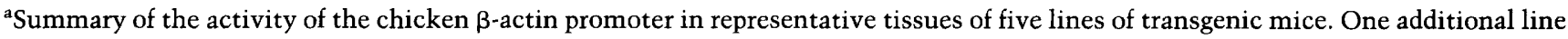
was made (AE16) that exhibited no detectable transgene expression.

b The DNAs driven by the $\beta$-actin promoter include the human EGF receptor cDNA (EGFR), the bacterial chloramphenicol acetyltransferase gene (CAT), and the human MDRl P-glycoprotein cDNA (MDR). CAT mice were analyzed by CAT protein assays and RNA primer extension; EGFR mice by RNase protection, Northern blotting, and primer extension; and MDR mice by slot and Northern blotting.

' (bm) Total bone in all mice except AM39, which was bone marrow; (br) brain; (h) heart; (i) intestine; (k) kidney; (li) liver; (lu) lung; $(\mathrm{mu})$ leg skeletal muscle; (ov) ovary plus uterus in all mice exept AC5 and AM39, which were ovary alone; (sp) spleen; (st) stomach; (te) testis.

$d_{(-)}$Undetectable expression; $(+)$trace expression. Each additional + represents an approximately two- to threefold higher amount of measurable RNA. These values are based on examination of between two and five mice per line. Quantitation is less precise between lines due to variation in methods used to analyze expression.

eData reproduced, with permission, from Galski et al. (1989).

shows that the signal, a 473-base protected RNA band, from AE24 testis was about three times higher than that obtained from $\mathrm{KB}$ cells and about one-tenth as strong as that obtained from A431 cells.

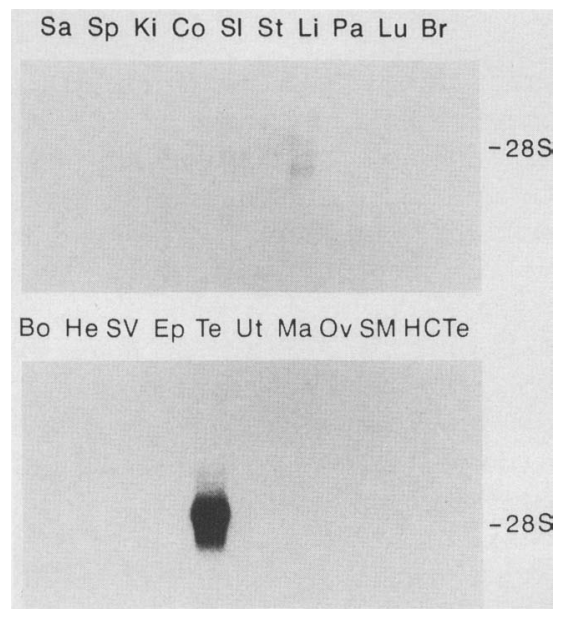

Figure 2. Northern blot analysis of EGF receptor transgene expression in tissues of AE24 homozygous mice. All samples contained $15 \mu \mathrm{g}$ of total RNA, except for ovary plus oviduct, which contained $13.5 \mu \mathrm{g}$. RNAs were electrophoretically fractionated on $0.8 \%$ agarose, transferred to nitrocellulose, and hybridized with the ${ }^{32} \mathrm{P}$-labeled pE7 insert. EGF receptor-specific RNA was visualized by autoradiography. Tissues: (Sa) Salivary gland; (Sp) spleen; (Ki) kidney; (Co) colon; (SI) small intestine; (St) stomach; (Li) liver; (Pa) pancreas; (Lu) lung; $(\mathrm{Br})$ brain; (Bo) bone marrow; (He) heart; (SV) seminal vesicle; (Ep) epididymis; (Te) testis; (Ut) uterus; (Ma) mammary gland; $(\mathrm{Ov})$ ovary plus oviduct; (SM) skeletal muscle; (HCTe) testis from high-copy line AE24HC. (28S) Migration of the mouse 28S rRNA.
To determine whether transcription of the EGF receptor cDNA was being correctly initiated within the chicken $\beta$-actin promoter, we performed primer extension analysis with a human EGF receptor-specific 25base oligonucleotide derived from the $5^{\prime}$ end of the EGF receptor cDNA. Extension of this EGF receptor primer by reverse transcriptase resulted in a single intense band of 374 bases (Fig. 3B, lane 1), which is exactly the size expected if transcription was initiating from the chicken $\beta$-actin promoter (Fig. 3C). Larger bands were virtually undetectable by this assay, indicating that strong EGF receptor transcription was not due to initiation from an endogenous mouse promoter located in the $5^{\prime}$-flanking region of the transgene. Extension of human A431 RNA resulted in the generation of a prominent band of 443 bases (Fig. 3B, lane 3), corresponding to the location of the major start of transcription of the endogenous human EGF receptor gene.

\section{Postmeiotic synthesis of the EGF receptor}

Localization of the human EGF receptor protein within the AE24 testis was achieved with a human-specific EGF receptor monoclonal antibody in conjunction with immunoperoxidase and immunogold staining. Figure 4 shows that EGF receptors were present only in stagespecific germ cells within the seminiferous tubules. EGF receptors first appeared in elongate spermatids at stage 9 of spermatogenesis and reached a maximal level at stages 11 and 12 (Fig. 4A,G). Higher magnification revealed that EGF receptors were located at the cell surface of late spermatids (Fig. 4I,J). EGF receptors were concentrated within residual bodies at stage 8 (Fig. 4B) and were observed at the base of Sertoli cells by stage 9, probably 


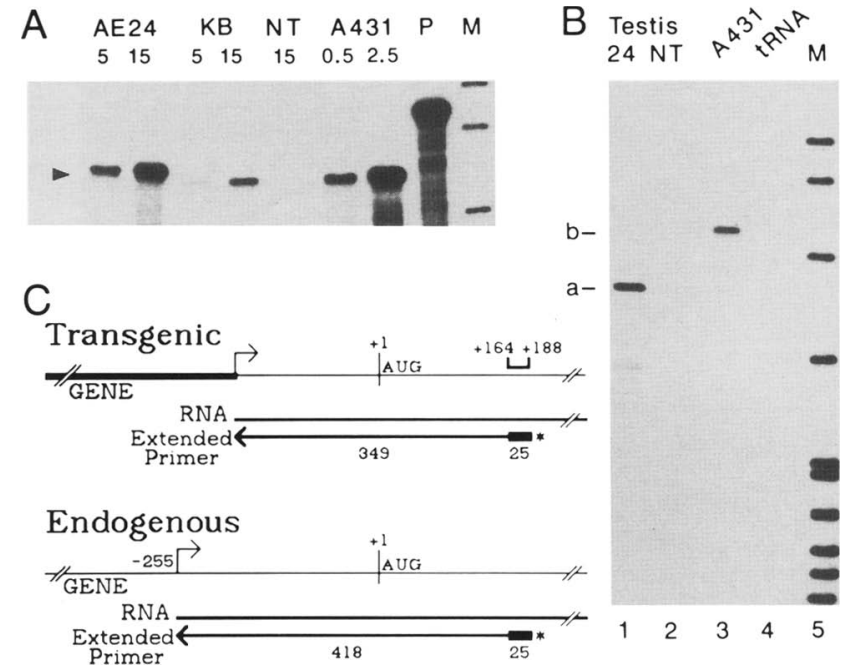

Figure 3. Analysis of AE24 transgenic RNA by RNase protection $(A)$ and primer extension $(B, C) .(A)$ Autoradiogram of a panel of RNA fragments generated by hybridizing a ${ }^{32} \mathrm{P}$-labeled riboprobe (Fig. 1D) to 5 or $15 \mu \mathrm{g}$ of AE24 testicular RNA, 5 or 15 $\mu \mathrm{g}$ of human KB cell RNA, $15 \mu \mathrm{g}$ of nontransgenic (NT) CD1 testicular RNA, and 0.5 or $2.5 \mu \mathrm{g}$ of human A431 cell RNA and digesting the resulting hybrids with RNases $A$ and $T_{1}$. The arrowhead marks the location of the protected 473-base humanspecific transgenic RNA. Lane $P$ contains the 546-base riboprobe alone. The radiolabeled markers shown in lane $M$ are 622 , 527 , and 404 bp. (B) Autoradiogram of extension of primer EGFR1 with reverse transcriptase and $20 \mu \mathrm{g}$ of AE24 testicular RNA (lane 1), $20 \mu \mathrm{g}$ of nontransgenic CDl testicular RNA (lane 2), $1.2 \mu \mathrm{g}$ of A431 cell RNA (lane 3), or $20 \mu \mathrm{g}$ of tRNA (lane 4). Markers shown in lane 5 are 622, 527, 404, 309, 242, 238, 217, 201, 190, and $180 \mathrm{bp}$. (a) Expected location of the 374-base transgene-specific extension product; $(b)$ expected location of the 443-base endogenous gene-specific product. $(C)$ Schematic representation of primer extension analysis of human EGF receptor RNA from transgenic mouse tissues and endogenous human A 431 cells. The thick black line represents the $\beta$-actin promoter region of the transgene. The thin arrow in the gene indicates the major transcription initiation site, and AUG $(+1)$ indicates the translation start site (Ishii et al. 1985; Johnson et al. 1988). The EGFR 1 primer is located at +164 to +188 (represented by a small black box), and the asterisk (*) depicts the location of the ${ }^{32} \mathrm{P}$ label. The extended primer is represented by the thick arrow.

because of phagocytosis of residual bodies (Fig. 4C; Clermont et al. 1987). EGF receptors could not be detected on the mature sperm by immunoperoxidase staining (Fig. 4B,C,J), colloidal gold staining (Fig. 4G,I), or immunofluorescence (data not shown); furthermore, no significant amount of peroxidase staining was associated with the epididymis (data not shown).

These results suggest that EGF receptor protein was made exclusively in postmeiotic elongate spermatids. To confirm this possibility, we subjected testes from juvenile 18-day-old AE24 mice, which contain spermatocytes but not haploid spermatids, and 25-day-old AE24 mice, which possess both spermatocytes and spermatids, to EGF receptor-specific immunoperoxidase staining. Receptors were observed only at day 25 (Fig. 4F), and not at day 18 (Fig. 4E), consistent with the notion that EGF receptors were not synthesized during germ-cell mitosis or meiosis.

\section{Translational control of testicular EGF receptor expression}

In situ hybridization was used to determine the pattern of EGF receptor RNA accumulation in the AE24 testis. In contrast to the results of the protein localization studies, human EGF receptor RNA transcripts were widely distributed throughout the seminiferous tubules but were conspicuously absent from interstitial Leydig cells and Sertoli cells (Fig. 5C,D,H). Grains were clearly seen over primary spermatocytes but not spermatogonial cells (Fig. $5 \mathrm{H}$ ), indicating that the EGF receptor transgene was transcriptionally active during meiosis. In situ hybridization was also used to show that EGF receptor RNA transcripts were readily detectable in primary spermatocytes of the testis from juvenile 18-day-old AE24 transgenic mice (Fig. 5A,B,G), which do not possess differentiating spermatids. These results confirmed that human EGF receptor RNA was being made considerably earlier than EGF receptor protein and that the transgene was being regulated by a translational control mechanism reminiscent of the regulation of the expression of many endogenous mouse testicular genes (Hecht 1990).

\section{Sterility and aberrant sperm axoneme structure in homozygotes}

Taken together, these results suggest that the AE24 EGF receptor transgene was integrated into a testis-specific gene. To determine whether insertion of this transgene caused a mutation that would compromise spermatogenesis, we generated homozygous mice. Five homozygous female mice were identified by Southern blot hybridization and by analysis of litters from backcross matings to nontransgenic animals. All five appeared completely normal and were fertile. Twelve homozygous male mice were identified by quantitative Southern blot hybridization, but seven of these were found to be sterile. Examination of the spermatozoa from sterile AE24 homozygous mice revealed grossly atypical motility. Dark-field video microscopy demonstrated dramatic differences in sperm samples from fertile versus sterile animals. Sperm from all nontransgenic mice, as well as heterozygous and fertile homozygous transgenic mice, exhibited a normal rapid bending motion throughout the length of the sperm flagella (Fig. 6A). In contrast, sperm from sterile homozygous transgenic mice possessed a rigid immobile middle piece, and rapid motion was restricted to the end piece and part of the principal piece (Fig. 6B).

Electron microscopy of sperm removed from the vas deferens of nontransgenic and sterile homozyous mice was used to determine the cause of their aberrant motility. Figure 7 shows a cross section through the middle piece of a typical nontransgenic sperm tail (A) and a sche- 

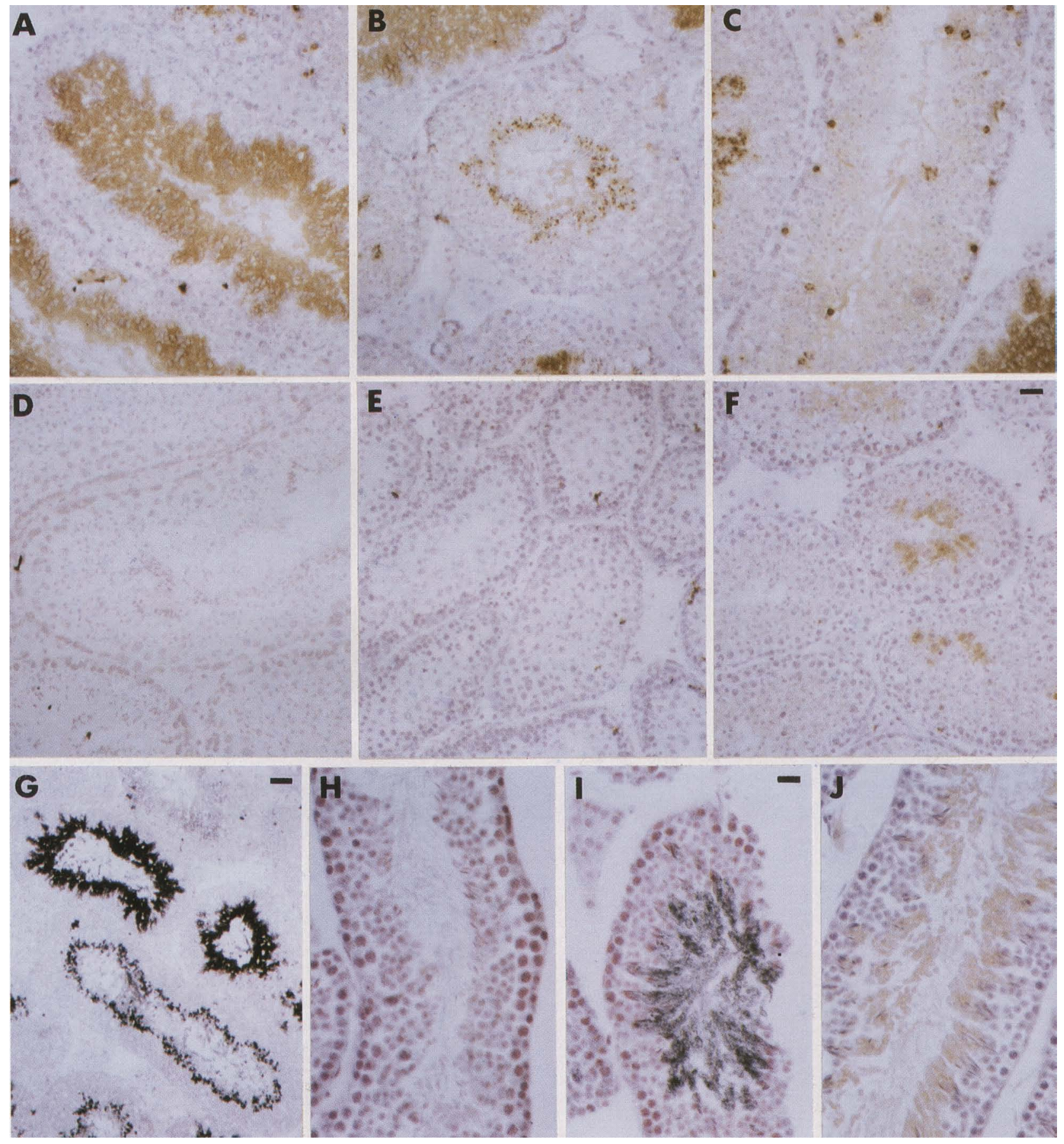

Figure 4. Immunohistochemical localization of the human EGF receptor in the testes of adult $(A-C, G-J), 25$-day-old juvenile $(F)$, and 18-day-old juvenile $(E)$ AE24 transgenic mice and an adult nontransgenic CD1 mouse $(D)$. Sections were made from either frozen $(A-G)$ or paraffin-embedded $(H-I)$ tissue. EGF receptor localization was done with either horseradish peroxidase $(A-F, I)$ or collodial gold $(G-I)$ staining. The antibodies used were anti-EGFR-PE $(A-G, I, J)$ or anti-PE alone $(H)$. Magnifications: $(A-F) 150 \times($ bar, $27 \mu \mathrm{m}) ;(G) 75 \times($ bar, $53 \mu \mathrm{m}) ;(H-I), 300 \times(\mathrm{bar}, 13 \mu \mathrm{m})$.

matic representation of this normal pattern $\left(A^{\prime}\right)$. Nontransgenic axonemal microtubules are arranged so that nine peripheral or outer doublets surround a single central pair $(9+2)$. In contrast, the majority of sperm from sterile homozygotes were missing some outer doublets and their corresponding associated structures, such as dynein arms and radial spokes, resulting in a $5+2$ pattern in the middle piece (Fig. $7 \mathrm{~B}, \mathrm{C}$ ). Because the outer 

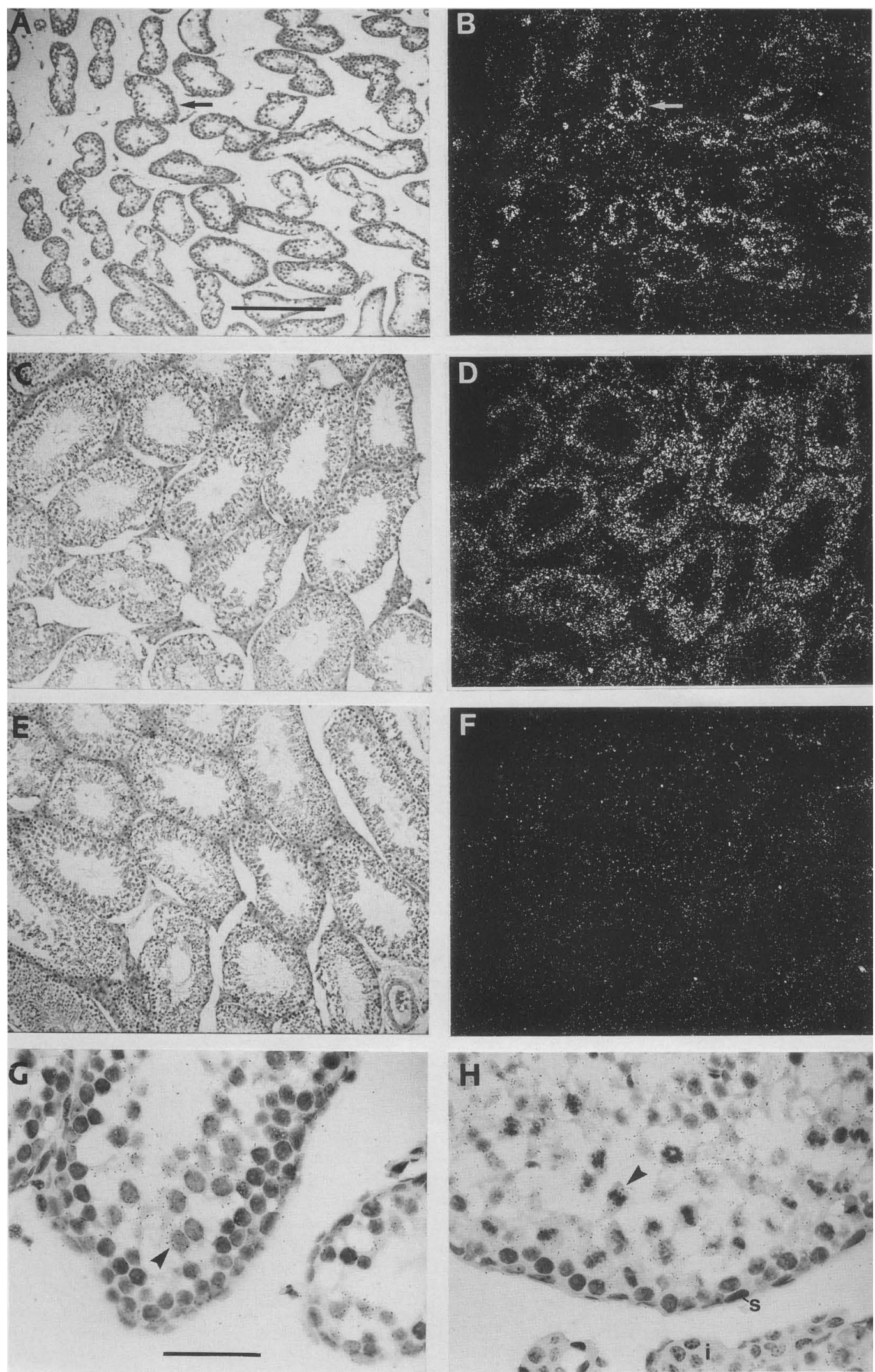

Figure 5. (See facing page for legend.) 

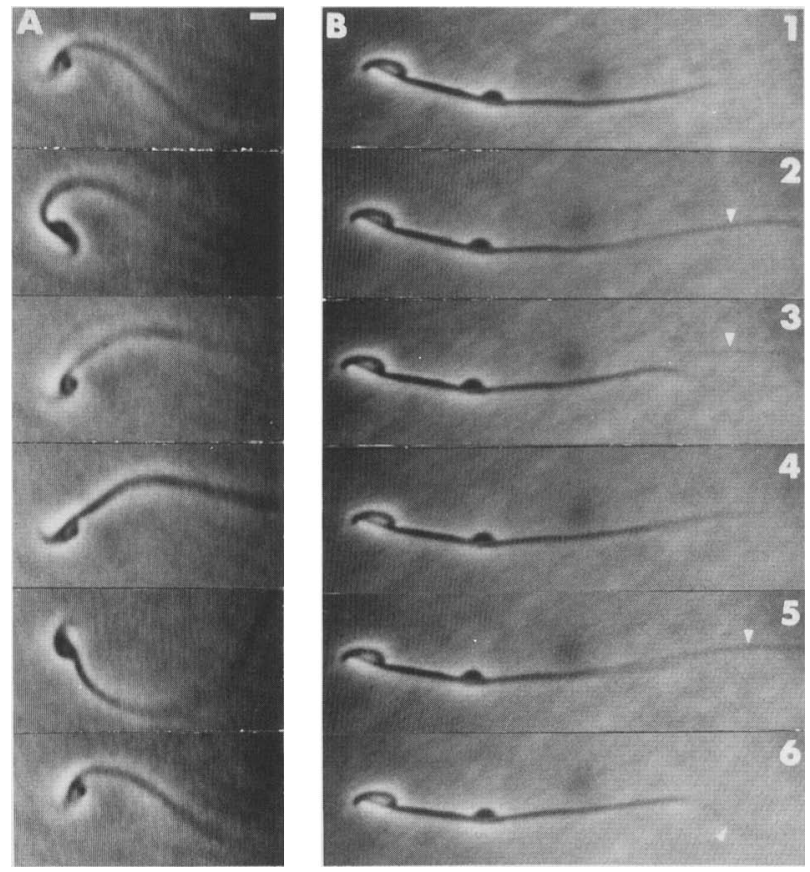

Figure 6. Video phase-contrast microscopy sequence of movement of sperm at $23^{\circ} \mathrm{C}$ from nontransgenic CD1 $|A|$ and homozygous sterile AE24 transgenic $(B)$ mice. The arrowheads indicate the moving principal piece of the paralyzed transgenic sperm. The time between each frame is $\sim 100 \mathrm{msec}$. Magnification, $1000 \times$ (bar, $4 \mu \mathrm{m}$ ).

dense bodies usually remained intact in these abnormal sperm, it could be determined that the missing microtubule pairs were usually numbers 4-7 (cf. Fig. 7B with $\mathrm{A}^{\prime}$ ). Other bizarre arrangements of microtubules could be seen in the middle and principal pieces at a lower frequency, including extra and misplaced outer doublets (data not shown). No overt abnormalities of the sperm head were observed.

Table 2 reveals that when middle-piece axonemes were analyzed from the sperm of three different sterile homozygotes, an average of $7 \%$ possessed the normal $9+2$ pattern, whereas an average of $71 \%$ were arranged as $5+2$. In contrast, the principal-piece axonemes of these abnormal sperm often possessed the $9+2$ arrangement (Table 2). Although a smaller number of end-piece axonemes were analyzed, over $90 \%$ of these were determined to be normally configured. Sperm tails from nontransgenic and AE24 heterozygous and fertile homozygous mice were completely normal (Table 2). Further-
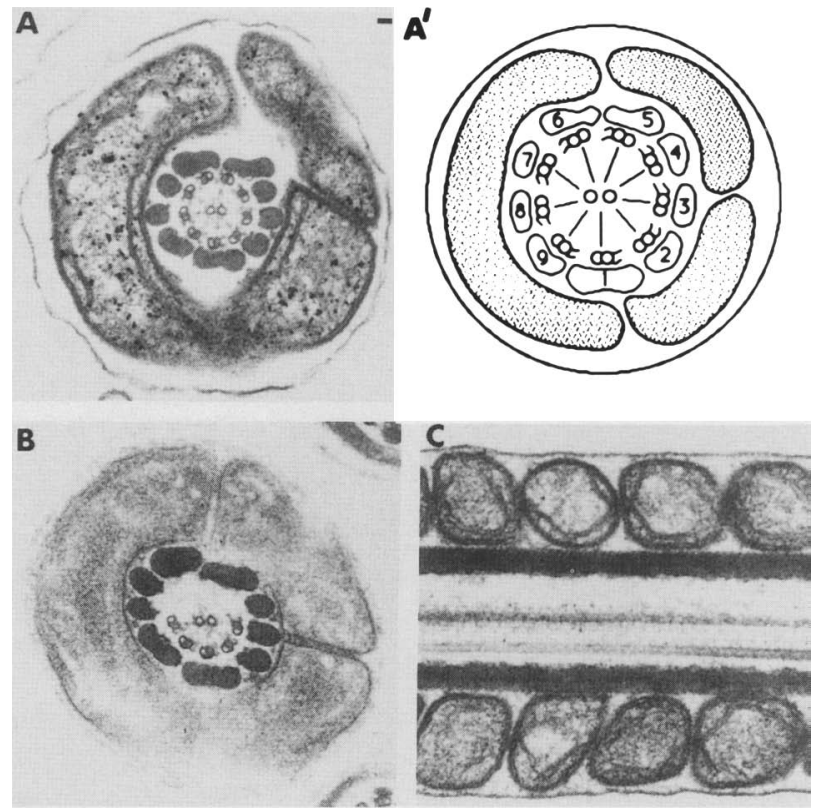

Figure 7. Electron microscopic analysis of middle-piece sections of sperm flagella from nontransgenic CD1 $(A)$ and homozygous sterile AE24 transgenic $(B, C)$ mice. Cross sections $(A, B)$ and a longitudinal section $(C)$ are shown. Magnification, $73,000 \times$; bar, $55 \mathrm{~nm}$. (A') Schematic depiction of a cross section through the middle piece of a sperm flagellum from a typical nontransgenic mouse.

more, cilia lining the bronchioles of sterile homozygous male mice also contained normal axonemes (data not shown).

To determine whether the gross abnormalities associated with immotile sperm axonemes were due to aberrant assembly or enhanced instability, we analyzed sperm from the vas deferens, caudal epididymis, caput epididymis and testis by electron microscopy. Figure 8 shows that although the vast majority of flagellar axonemes in the sperm from the vas deferens and epididymis possessed atypical microtubule patterns (usually $5+2$ or $6+2$ ), sperm flagellar axonemes in the testis were generally found to be normal. These results suggest that sperm axonemes are assembled in a grossly normal fashion but undergo extensive microtubule disruption and/or disassembly after spermiation.

\section{Discussion}

Translational control

In this report we describe the generation of a number of

Figure 5. Localization of human EGF receptor RNA transcripts in the testis of 18-day-old juvenile $(A, B, G)$ and adult $(C-F, H)$ AE24 transgenic $(A-D, G, H)$ and nontransgenic CD1 $(E, F)$ mice by in situ hybridization. Bright-field illumination is depicted in $A, C, E, G$, and $H$; dark-field illumination is depicted in $B, D$, and $F$. The hybridization probe was a ${ }^{35} \mathrm{~S}$-labeled antisense riboprobe derived from pEGFR-RP. Hybridization with a ${ }^{35}$ S-labeled sense probe resulted in no specific pattern and low background (data not shown). An example of a labeled juvenile seminiferous tubule is shown by the arrows in $A$ and $B$. Arrowheads in $G$ and $H$ indicate labeled primary spermatocyes. Note the primary spermatocytes with condensed chromosomes in $H$. (i and s) Locations of unlabeled interstitial cells and spermatogonia, respectively $(H)$. Magnifications: $(A-F) 98 \times($ bar, $250 \mu \mathrm{m}) ;(G, H) 615 \times($ bar, $40 \mu \mathrm{m})$. 
Table 2. Distribution of peripheral microtubules in transgenic sperm axonemes

\begin{tabular}{|c|c|c|c|c|c|c|c|c|c|c|}
\hline & \multicolumn{10}{|c|}{$\begin{array}{c}\text { Number of peripheral doublets/flagellar cross section } \\
\text { (percent of total in each category) }\end{array}$} \\
\hline & 0 & 1 & 4 & 5 & 6 & 7 & 8 & 9 & 10 & 14 \\
\hline Nontransgenic & 0 & 0 & 0 & 0 & 0 & 0 & 0 & 100 & 0 & 0 \\
\hline Heterozygote & 0 & 0 & 0 & 0 & 0 & 0 & 0 & 100 & 0 & 0 \\
\hline Homozygote fertile & 0 & 0 & 0 & 0 & 0 & 0 & 0 & 100 & 0 & 0 \\
\hline Homozygote sterile 1 & 0 & 0 & 0 & 72 & 15 & 3 & 5 & 4 & 0 & 1 \\
\hline Homozygote sterile 2 & 4 & 2 & 2 & 57 & 9 & 4 & 5 & 16 & 1 & 0 \\
\hline Homozygote sterile 3 & 1 & 0 & 1 & 86 & 6 & 1 & 4 & 1 & 0 & 0 \\
\hline Homozygote sterile 3 (prin.) & 0 & 0 & 0 & 0 & 0 & 1 & 15 & 82 & 1 & 1 \\
\hline
\end{tabular}

Data were generated from electron microscopy analysis of ultrathin sections of sperm collected from the vas deferens of CD1 nontransgenic and AE24 transgenic heterozygous and homozygous mice. Microtubule outer doublets were counted only in the sperm middle piece except in the last line, where microtubules were counted from the principal piece (prin.) of sterile homozygote 3. One hundred cross sections were counted for each group, except in the heterozygote, where 50 were counted.

transgenic mice bearing a human EGF receptor cDNA driven by the chicken $\beta$-actin promoter. One unique line (AE24) possessed extremely strong EGF receptor gene expression in the testis and weak or undetectable expression in all other organs, suggesting that the transgene was being influenced by an adjacent endogenous testisspecific enhancer. Expression of the human EGF receptor cDNA was regulated by a translational control mechanism, reminiscent of the regulation of testis-specific mouse genes such as protamine 1 , protamine 2 , and transition protein 1 (for review, see Hecht 1990). Human EGF receptor RNA was detected in spermatocytes and spermatids, whereas EGF receptor protein first appeared postmeiotically in late, elongate spermatids.

Recent evidence indicates that the $3^{\prime}$-untranslated region of mRNAs transcribed from testis-specific genes such as protamine 1 and protamine 2 contains sequences that are essential for translational control (Braun et al. 1989; Hecht 1990). The fact that the EGF receptor transgene in AE24 mice is under translational regulation raises the possibility that transcription can continue through the polyadenylation signal of the LTR and terminate within the 3 '-flanking region, thereby creating a novel hybrid RNA transcript possessing a powerful translational control signal. This notion is supported by the finding that the size of the transgenic EGF receptor RNA was greater than expected, despite transcription starting at the correct transgene promoter initiation site. Alternatively, translation could be influenced by the secondary structure of EGF receptor RNA sequences. For this issue to be resolved, the $3^{\prime}$-flanking region of the transgene integration site must be isolated and sequenced.

\section{EGF receptor transit and compartmentalization during spermiogenesis}

The human EGF receptor should serve as a useful marker in the analysis of the synthesis, processing, and degradation of membrane-bound cell surface proteins during spermatogenesis. The receptor was first detected at the cell surface of postmeitoic elongate spermatids and was
Figure 8. Distribution of peripheral microtubule doublets in the middle piece of a sperm flagellum from homozygous sterile AE24 transgenic mouse number 3 /see Table 2). Sperm samples from the testis (solid area), caput epididymis, (open hatching), caudal epididymis (open area), and vas deferens (shaded hatching) were analyzed by electron microscopy. Sperm were removed from the vas deferens and concentrated by brief centrifugation before fixation.

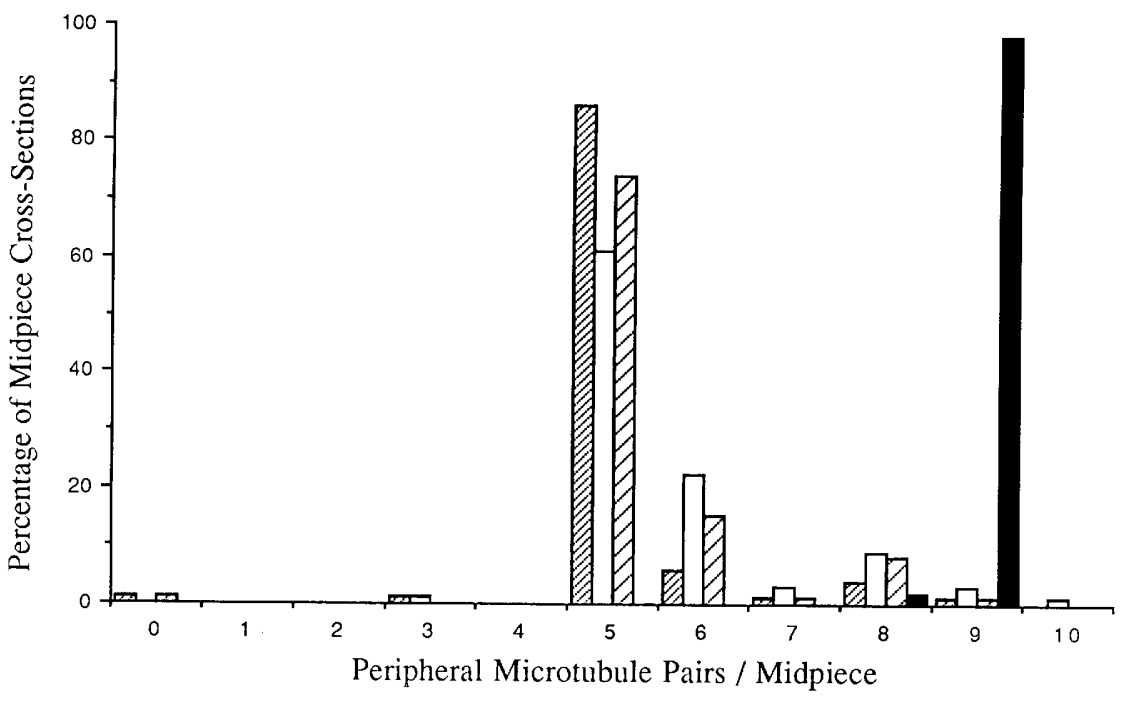


subsequently concentrated in residual bodies. EGF receptor-laden residual material was then phagocytized by Sertoli cells. The receptor could not be detected on mature sperm, suggesting that during spermiogenesis a compartmentalization mechanism segregates EGF receptor-containing membranes into residual bodies and away from spermatozoa and supporting the idea that sperm membranes are highly specialized and are the product of extensive maturation-related processing (Friend 1989; Bearer and Friend 1990).

\section{Insertional mutagenesis and male sterility}

These results raise the possibility that the EGF receptor transgene was integrated directly into an important testis-specific gene. This notion was strongly supported by the discovery that homozygous AE24 male mice were frequently sterile, apparently because of microtubule aberrations in sperm flagellar axonemes, whereas axonemes of the bronchiolar cilia in these sterile male homozygotes were structurally normal. The endogenous gene could encode a highly expressed, haploid-specific axonemal protein or, alternatively, a protein that indirectly dictates axonemal stability.

Although it is possible that EGF receptor overexpression also contributed to the appearance of the sterile phenotype, the presence of a vast excess of EGF receptors during sperm formation cannot be sufficient to cause sterility because heterozygous AE24 male mice have always been found to be fertile ( 45 of 45 heterozygotes tested possessed normal sperm) despite possessing extremely high receptor levels. Heterozygous mice exhibited no obvious phenotypic alterations in the testis or in any other organ. The testis was also found to be phenotypically normal in doubly transgenic mice made by crossing AE24 with MT42 (data not shown), which overexpresses TGF $\alpha$ in many tissues, including the testis (Jhappan et al. 1990). Presumably, elongate spermatids are not affected by the presence of excess ligand or receptor because they are differentiated and are no longer capable of a proliferative response.

\section{Incomplete penetrance of the sterile phenotype}

Homozygous AE24 male mice exhibited incomplete penetrance with respect to the sterile phenotype. Of the 12 homozygous male mice generated by heterozygote matings, 7 were sterile and possessed aberrant sperm axonemes, whereas 5 were fertile and possessed normal sperm axonemes. The reason for the incomplete penetrance of this phenotype is not known. The existence of two linked insertion sites has been refuted by Southern blot analysis of transgene flanking regions /data not shown). There is substantial genotypic variability within the AE24 outbred line, which could lead to the independent assortment of secondary genetic elements affecting fertility. Expression of the sterile phenotype in male mice can be strictly dependent on genetic background, including sterility associated with the $t$ complex, the hybrid sterility genes 1 and 2 (Hst-1 and Hst-2), and spe- cific autosomal chromosomal translocations (Forejt and Ivanyi 1975; Forejt 1976; Olds-Clarke and McCabe 1982; deBoer 1986; Olds-Clarke 1988).

Preliminary analysis of $F_{1}$ and $F_{2}$ progeny generated from matings between five fertile homozygous AE24 male mice and five homozygous AE24 female mice corroborates the dependency on genetic background. Of 38 homozygous male pups tested to date, $74 \%$ (28) possess normal sperm but $26 \%$ (10) contain grossly aberrant sperm. Some mating combinations resulted in the generation of all fertile male mice, whereas others produced about half fertile male mice. These results suggest that the expression of a second unlinked gene can obviate the need for the normal endogenous gene product. The genetic rescue of paralyzed axonemes has been described in Chlamydomonas cilia and may also help explain reproductive variations among male mice possessing different $t$ haplotypes (Huang et al. 1982; Handel 1987; OldsClarke 1988).

\section{Defective sperm motility and axoneme disruption}

Many mutations associated with defective male fertility caused by abnormal spermatogenesis have been described; however, these lines of mice are characterized by a constellation of phenotypic abnormalities (Handel 1987; Green 1989|. In contrast, homozygous AE24 transgenic mice only expressed a sterile male phenotype. Furthermore, although most mutant mice with aberrant sperm tail structure also exhibit abnormal sperm head morphology (Handel 1987; Green 1989), the heads of homozygous AE24 spermatozoa appeared to be normal by light and electron microscopic examinations (data not shown).

The electron microscopic data presented in this report suggest that sperm flagellar axonemes are assembled appropriately and appear to be normal in the sterile homozygous testis but possess a latent instability and undergo microtubule disassembly upon release from Sertoli cells and/or entry into the epididymis. In certain $t$ haplotypes and the Wobbler mutation $(w r)$, sperm microtubules are also arranged in aberrant patterns in the vas deferens but appear to be normal in the testis (Dooher and Bennett 1977; Leestma and Sepsenwol 1980). The defective nature of these mutant sperm may become manifest in the epididymis because at this time they undergo dramatic changes in morphology and biochemistry and acquire motility (Hoskins and Vijayaraghavan 1990). Interestingly, sperm tail axonemes from both $w r /$ wr and sterile AE24 mice usually contain the same microtubule pattern $(5+2)$ and are missing the same outer doublets (4-7) (Leestma and Sepsenwol 1980).

Mutations leading to sperm paralysis and male sterility have been described in humans as well as in mice (Ryder et al. 1990). The best described disease is immotile-cilia (Kartagener's) syndrome, in which men suffer from chronic sinobronchial infections and abnormal motility of both respiratory cilia and sperm flagella (Eliasson et al. 1977). In this case, sperm flagellar outer doublet microtubules are normal, and paralysis is caused by 
the absence of dynein arms (Eliasson et al. 1977). However, a relationship between the loss of axonemal microtubule doublets and sterility has been established by Escalier and David (1984), who used quantitative ultrastructural analysis to study the ejaculates from 56 sterile men. They found that $43 \%(24)$ of the ejaculates contained sperm that were missing outer-doublet microtubules and corresponding peripheral junctions; and in over $90 \%$ (22) of these cases, doublets 4-7 were absent, resulting in an aberrant axonemal pattern identical to that seen in sperm axonemes from sterile AE24 homozyotes $(5+2)$. The manifestation of male sterility in both humans and mice because of the loss of specific sperm tail outer doublets raises the possibility that the endogenous gene inactivated in line AE24 by insertion of the EGF receptor transgene possesses an important and conserved function in sperm motility. Identification of a gene whose function is restricted to spermatogenesis should greatly aid in the molecular dissection of this complex process.

\section{Materials and methods \\ DNA constructions}

The DNA fragment used for microinjection is shown in Figure 1A. A $4.9-\mathrm{kbp} \mathrm{XbaI-PvuI} \mathrm{fragment} \mathrm{containing} 4.06 \mathrm{kbp}$ of human EGF receptor cDNA (Merlino et al. 1985) and $0.4 \mathrm{kbp}$ of the Abelson MuLV LTR polyadenylation signal (SmaI-PvuI; Reddy et al. 1983) was removed pMMTV-EGFR (Clark et al. 1986) and ligated into the $\mathrm{XbaI}-\mathrm{HincII}$ sites of pUC19 to generate plasmid pEGFR0. A 0.34-kbp SalI-SalI chicken $\beta$-actin promoter fragment was removed from p8CAT (generously provided by $\mathrm{B}$. Paterson; Quitschke et al. 1989), converted to $X b a$ I by linker ligation, and inserted into the $X b a I$ site of pEGFRO in the correct orientation, creating plasmid $p \beta A$-EGFR. Plasmid $p E G F R$ $\mathrm{RP}$ was constructed for synthesizing riboprobes by inserting a 473-bp XbaI-PstI MMTV-EGFR fragment (EGF receptor cDNA from -158 to +314 , where AUG is +1 ; Ishii et al. 1985; Merlino et al. 1985) into the XbaI-Pst sites of pGEM3 (Fig. ID).

\section{DNA microinjection and generation of transgenic mice}

Plasmid DNAs were prepared by standard $\mathrm{CsCl}$ centrifugation techniques. p $\beta$ A-EGFR was digested with PvuI and HindIII to release the 4.95-kbp microinjection fragment (Fig. 1A). DNA fragments, purified as described previously (Jhappan et al. 1990), were microinjected into the pronuclei of one-cell mouse embryos, isolated in Brinster's BMOC-3 medium (GIBCO) from the outbred strain CD1 (Charles River) as described by Hogan et al. (1986). Surviving embryos were transferred into CD1 pseudopregnant foster mothers. Southern blot analysis of tail genomic DNA (Hogan et al. 1986) was used to identify transgenic founders. The 2.4-kbp ClaI-ClaI insert from the EGF receptor cDNA-containing plasmid pE7 (Fig. 1B) was used as a hybridization probe (Xu et al. 1984; Merlino et al. 1985). Homozygous mice were identified by quantitative Southern blot hybridization, and homozygosity was confirmed in fertile mice by backcrossing to nontransgenic animals.

\section{Preparation and analysis of RNA}

Total RNA was isolated from various mouse tissues as described previously (Jhappan et al. 1990). Human EGF receptor- specific RNase protection assays were performed with a uniformly labeled riboprobe, made with the PvuII-linearized pEGFR-RP template plasmid, SP6 polymerase, and $\left[\alpha{ }^{-32} \mathrm{P}\right] \mathrm{GTP}$ as described by the manufacturer (Promega). The 546-base RNA riboprobe was incubated overnight at $42^{\circ} \mathrm{C}$ with $15 \mu \mathrm{g}$ of total RNA, and the resulting RNA hybrids were exposed to RNases A and $\mathrm{T}_{1}$ at $30^{\circ} \mathrm{C}$ for $1 \mathrm{hr}$. Under these conditions, the endogenous mouse EGF receptor was not detectable. Northern blot analysis was performed as described elsewhere (Xu et al. 1984; Merlino et al. 1985). Blots were stripped and rehybridized with a $\gamma$-actin probe to quantify RNA. RNA sizes were determined by comparison with mouse rRNAs and an RNA ladder (Bethesda Research Laboratories). Primer extension analysis was carried out as described previously (Merlino et al. 1982; Johnson et al. 1988), except that the 25-base oligonucleotide EGFR1 (Fig. 3) was hybridized to total RNA in $40 \%$ formamide, $0.4 \mathrm{M} \mathrm{NaCl}, 1$ mM EGTA, and $40 \mathrm{~mm}$ PIPES (pH 6.4) at $42^{\circ} \mathrm{C}$ for $3 \mathrm{hr}$ (Johnson et al. 1988). Extended radiolabeled DNA and RNase-protected RNA fragments were visualized by urea $-4 \%$ polyacrylamide gel electrophoresis and autoradiography.

\section{In situ RNA hybridization}

The hybridization procedure was a modification of that described by Nakamura et al. (1989). Sections of paraffin-embedded testes were hybridized with ${ }^{35}$ S-labeled RNA transcripts synthesized from the linearized pEGFR-RP plasmid with SP6 and $\mathrm{T} 7$ polymerases to generate antisense and sense probes, respectively. Transcription conditions were those described by the manufacturer (Promega). Hybridization was done at a probe concentration of $1.25 \times 10^{5} \mathrm{dpm} / \mathrm{ml}(10 \mu \mathrm{l}$ per slide $)$. Slides were exposed to Kodak NTB-2 emulsion for 3-21 days.

\section{Histology and immunocytochemistry}

Staging of testicular cells was done as described by Russell et al. (1990). Tissues from transgenic and normal mice were either frozen for the preparation of cryostat sectioning or fixed in formaldehyde. Cryostat sections were air-dried and fixed in acetone. All antibody incubations included $0.1 \%$ saponin, $4 \mathrm{mg} / \mathrm{ml}$ of normal goat globulin, and PBS. A mouse monoclonal antibody specific for the human EGF receptor (no. 528) was generously provided by J. Mendelson (Masui et al. 1984). A conjugate (antiEGFR-PE) of this antibody with Pseudomonas exotoxin (as a hapten) was the generous gift of I. Pastan and J. Batra (Batra et al. 1989). The labeling sequence was as follows: anti-EGFR-PE at 1 $\mu \mathrm{g} / \mathrm{ml}$, rabbit anti-Pseudomonas exotoxin (anti-PE) (the generous gift of D. FitzGerald and I. Pastan) at $2 \mu \mathrm{g} / \mathrm{ml}$, and goat anti-rabbit immunoglobulin G conjugated with either horseradish peroxidase (5 $\mu \mathrm{g} / \mathrm{ml}$; Jackson ImmunoResearch) or $1 \mathrm{~nm}$ of colloidal gold (Janssen Auroprobe; $1: 100$ dilution); labeling was done at room temperature for $60 \mathrm{~min}$. Peroxidase-labeled sections were developed with diaminobenzidine (Sigma) and osmium tetroxide. Colloidal gold-labeled sections were developed with Intense (Janssen) silver enhancement for $25 \mathrm{~min}$.

\section{Observations of sperm motility}

Male mice that mated to fertile nontransgenic female mice but produced no offspring were judged to be sterile. Suspensions of living sperm were placed under a coverslip in either PBS or Dulbecco's culture medium and examined at room temperature by using phase-contrast microscopy and video recording. Selected images were photographed at $\sim 100$-msec intervals to produce the pictures shown in Figure 6. 


\section{Electron microscopy}

Tissues and sperm pellets were fixed in 3\% glutaraldehyde in PBS, treated with $1 \%$ osmium tetroxide, dehydrated in ethanol and propylene oxide, and embedded in Epon 812. Thin sections were stained with uranyl acetate and lead citrate and viewed with a Philips 400 T electron microscope.

\section{Acknowledgments}

We thank Ira Pastan, Hitoshi Takagi, Michael Gottesman, Alfred Johnson, Paul Overbeek, Grant MacGregor, George Gerton, Norman Hecht, Mary Ann Handel, and Mark Johnson for useful discussions and/or reading of the manuscript. We thank Eugene Chu, Betty Lovelace, and Richard Sharp for technical assistance, Bruce Paterson for the chicken $\beta$-actin promoter, J. Batra for the antibody-toxin conjugate anti-EGFR-PE, and John Mendelson for the EGF receptor monoclonal antibody. In particular, we are indebted to Marvin Meistrich for assistance in the staging of testicular cell types and for many fruitful discussions.

The publication costs of this article were defrayed in part by payment of page charges. This article must therefore be hereby marked "advertisement" in accordance with 18 USC section 1734 solely to indicate this fact.

\section{References}

Batra, J.K., Y. Jinno, V.J. Chaudhary, T. Kondo, M.C. Willingham, D.J. FitzGerald, and I. Pastan. 1989. Antitumor activity in mice of an immunotoxin made with anti-transferrin receptor and a recombinant form of Pseudomonas exotoxin. Proc. Natl. Acad. Sci. 86: 8545-8549.

Bearer, E.L. and D.S. Friend. 1990. Morphology of mammalian sperm membranes during differentiation, maturation, and capacitation. I. Electron Microsc. Tech. 16: 281-297.

Braun, R.E., J.J. Peschon, R.R. Behringer, R.L. Brinster, and R.D. Palmiter. 1989. Protamine $3^{\prime}$-untranslated sequences regulate temporal translational control and subcellular localization of growth hormone in spermatids of transgenic mice. Genes \& Dev. 3: 793-802.

Clark, A.J.L., L. Beguinot, S. Ishii, D.P. Ma, B.A. Roe, G.T. Merlino, and I. Pastan. 1986. Synthesis of epidermal growth factor (EGF) receptor in vitro using SP6 RNA polymerase-transcribed template mRNA. Biochim. Biophys. Acta 867: 244 251.

Clermont, Y., C. Morales, and L. Hermo. 1987. Endocytic activities of Sertoli cells in the rat. Ann. N.Y. Acad. Sci. 513: 115.

Costantini, F., G. Radice, J.L. Lee, K.K. Chada, W. Perry, and H.J. Son. 1989. Insertional mutations in transgenic mice. Prog. Nucleic Acids Res. Mol. Biol. 36: 159-169.

deBoer, P. 1986. Chromosomal causes for fertility reduction in mammals. In Chemical mutagens (ed. F.J. deSerres), Vol. 10, pp. 427-467. Plenum Press, New York.

Dooher, G.B. and D. Bennett. 1977. Spermiogenesis and spermatozoa in sterile mice carrying different lethal $\mathrm{T} / \mathrm{t}$ locus haplotypes: A transmission and scanning electron microscopic study. Biol. Reprod. 17: 269-288.

Eliasson, R., B. Mossberg, P. Camner, and B.A. Afzelius. 1977. The immotile-cilia syndrome. A congenital ciliary abnormality as an etiologic factor in chronic airway infections and male sterility. N. Engl. J. Med. 297: 1-6.

Escalier, D. and G. David. 1984. Pathology of the cytoskeleton of the human sperm flagellum: Axonemal and peri-axonemal anomalies. Biol. Cell 50: 37-52.
Forejt, J. 1976. Spermatogenic failure of translocation heterozygotes affected by $\mathrm{H}$-2-linked gene in mouse. Nature 260: $143-145$.

Forejt, J. and P. Ivanyi. 1975. Genetic studies on male sterility of hybrids between laboratory and wild mice (Mus musculus L.). Genet. Res. 24: 189-206.

Friend, D.S. 1989. Sperm maturation: Membrane domain boundaries. Ann. N.Y. Acad. Sci. 567: 208-221.

Galski, H., M. Sullivan, M.C. Willingham, K.-V. Chin, M.M. Gottesman, I. Pastan, and G.T. Merlino. 1989. Expression of a human multidrug resistance cDNA (MDR1) in the bone marrow of transgenic mice: Resistance to daunomycin-induced leukopenia. Mol. Cell. Biol. 9: 4357-4363.

Gordon, J.W., J. Uehlinger, N. Dayani, B.E. Talansky, M. Gordon, G.S. Rudomen, and P.E. Neumann. 1990. Analysis of the hotfoot (ho) locus by creation of an insertional mutation in a transgenic mouse. Dev. Biol. 137: 349-358.

Green, M.C. 1989. Catalog of mutant genes and polymorphic loci. In Genetic variants and strains of the laboratory mouse, 2nd ed. (ed. M.F. Lyon and A.G. Searle), pp. 12-403. Oxford University Press, Oxford.

Handel, M.A. 1987. Genetic control of spermatogenesis in mice. In Spermatogenesis: Genetic aspects (ed. W. Hennig), pp. 1-62. Springer-Verlag Press, Berlin.

Hecht, N.B. 1986. Regulation of gene expression during mammalian spermatogenesis. In Experimental approaches to mammalian embryonic development (ed. J. Rossant and R. Pedersen), pp. 151-193. Cambridge University Press, New York.

- 1990. Regulation of "haploid expressed genes" in male germ cells. J. Reprod. Fertil. 88: 679-693.

Hogan, B., F. Costantini, and E. Lacy. 1986. Manipulating the mouse embryo: A laboratory manual. Cold Spring Harbor Laboratory, Cold Spring Harbor, New York.

Hoskins, D.D. and S. Vijayaraghavan. 1990. A new theory on the acquisition of sperm motility during epididymal transit. In Controls of sperm motility: Biological and clinical aspects (ed. C. Gagnon), pp. 53-62. CRC Press, Boca Raton, Florida.

Huang, B., Z. Ramanis, and D.J.L. Luck. 1982. Suppressor mutations in Chlamydomonas reveal a regulatory mechanism for flagellar function. Cell 28: 115-124.

Ishii, S., Y.-H. Xu, R.H. Stratton, B.A. Roe, G.T. Merlino, and I. Pastan. 1985. Characterization and sequence of the promoter region of the human epidermal growth factor receptor gene. Proc. Natl. Acad. Sci. 82: 4920-4924.

Jhappan, C., C. Stahle, R.N. Harkins, N. Fausto, G.H. Smith, and G.T. Merlino. 1990. TGF $\alpha$ overexpression in transgenic mice induces liver neoplasia and abnormal development of the mammary gland and pancreas. Cell 61: 1137-1146.

Johnson, A.C., Y. Jinno, and G.T. Merlino. 1988. Modulation of epidermal growth factor receptor proto-oncogene transcription by a promoter site sensitive to S1 nuclease. Mol. Cell. Biol. 8: 4174-4184.

Krulewski, T.F., P.E. Neumann, and J.W. Gordon. 1989. Insertional mutation in a transgenic mouse allelic with Purkinje cell degeneration. Proc. Natl. Acad. Sci. 86: 3709-3712.

Leestma, J.E. and S. Sepsenwol. 1980. Sperm tail axoneme alterations in the Wobbler mouse. I. Reprod. Fertil. 58: 267270.

MacGregor, G.R., L.D. Russell, M.E. Van Beek, G.R. Hanten, M.J. Kovac, C.A. Kozak, M.L. Meistrich, and P.A. Overbeek. 1990. Symplastic spermatids (sys): A recessive insertional mutation in mice causing a defect in spermatogenesis. Proc. Natl. Acad. Sci. 87: 5016-5020.

Masui, H., T. Kawamoto, J.D. Sato, B. Wolf, G. Sato, and J. Mendelson. 1984. Growth inhibition of human tumor cells 
in athymic mice by anti-epidermal growth factor receptor monoclonal antibodies. Cancer Res. 44: 1002-1007.

Merlino, G.T. 1990. Epidermal growth factor receptor regulation and function. In Seminars in cancer biology (ed. R.B. Dickson and M.E. Lippman|, vol. 1, pp. 277-284. W.B. Saunders, Philadelphia.

Merlino, G.T., J.S. Tyagi, B. deCrombrugghe, and I. Pastan. 1982. Transcription of the chicken $\alpha 2$ (type I) collagen gene by homologous cell-free extracts. J. Biol. Chem. 257: 7254 7261.

Merlino, G.T., S. Ishii, J. Whang-Peng, T. Knutsen, Y.-H. Xu, A.J.L. Clark, R.H. Stratton, R.K. Wilson, D.P. Ma, B.A. Roe, J.H. Hunts, N. Shimizu, and I. Pastan. 1985. Structure and localization of genes encoding aberrant and normal epidermal growth factor receptor RNAs from A431 human carcinoma cells. Mol. Cell. Biol. 5: 1722-1734.

Nakamura, T., K.A. Mahon, R. Miskin, A. Dey, T. Kuwabara, and H. Westphal. 1989. Differentiation and oncogenesis: Phenotypically distinct lens tumors in transgenic mice. New Biologist 1: 193-204.

Olds-Clarke, P. 1988. Genetic analysis of sperm function in fertilization. Gamete Res. 20: 241-264.

Olds-Clarke, P. and S. McCabe. 1982. Genetic background affects expression of haplotype in mouse sperm. Genet. Res. 40: $249-254$.

Quitschke, W.W., Z.Y. Lin, L. DePonti-Zilli, and B.M. Paterson. 1989. The beta actin promoter. High levels of transcription depend upon a CCAAT binding factor. I. Biol. Chem. 264: 9539-9546.

Reddy, E.P., M.J. Smith, and A. Srinivasan. 1983. Nucleotide sequence of Abelson murine leukemia virus genome: Structural similarity of its transforming gene product to other onc gene products with tyrosine-specific kinase activity. Proc. Natl. Acad. Sci. 80: 3623-3627.

Russell, L.V., R. A. Ettlin, A. P. Sinha hikim, and E. D. Clegg. 1990. Histological and histopathological evaluation of the testis. Cache River Press, Clear Water, Florida.

Ryder, T.A., M.A. Mobberley, L. Hughes, and W.F. Hendry. 1990. A survey of the ultrastructural defects associated with absent or impaired sperm motility. Fertil. Steril. 53: 556560.

Shawlot, W., M.J. Siciliano, R.L. Stallings, and P.A. Overbeek. 1989. Insertional inactivation of the downless gene in a family of transgenic mice. Mol. Biol. Med. 6: 299-307.

Woychik, R.P., R.L. Mass, R. Zeller, T.F. Vogt, and P. Leder. 1990. "Formins": Proteins deduced from the alternative transcripts of the limb deformity gene. Nature 346: 850-853.

Xiang, X., K.F. Benson, and K. Chada. 1990. Mini-mouse: Disruption of the pygmy locus in a transgenic insertional mutant. Science 247: 967-969.

Xu, Y.-H., N. Richert, S. Ito, G.T. Merlino, and I. Pastan. 1984. Characterization of epidermal growth factor receptor gene expression in malignant and normal human cell lines. Proc. Natl. Acad. Sci. 81: 7308-7312. 


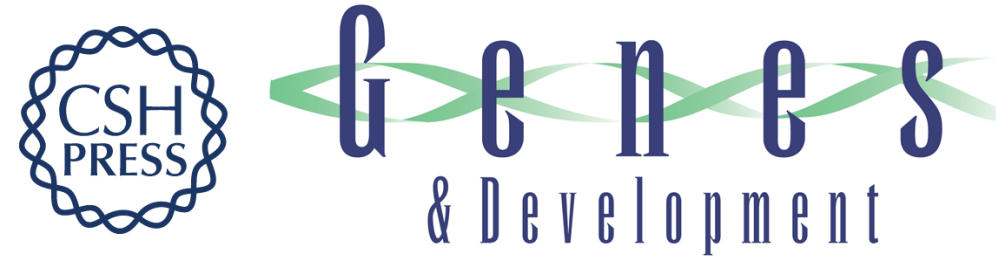

\section{Inactivation of a sperm motility gene by insertion of an epidermal growth factor receptor transgene whose product is overexpressed and compartmentalized during spermatogenesis.}

G T Merlino, C Stahle, C Jhappan, et al.

Genes Dev. 1991, 5:

Access the most recent version at doi:10.1101/gad.5.8.1395

References This article cites 35 articles, 16 of which can be accessed free at:

http://genesdev.cshlp.org/content/5/8/1395.full.html\#ref-list-1

License

Email Alerting Receive free email alerts when new articles cite this article - sign up in the box at the top Service right corner of the article or click here.

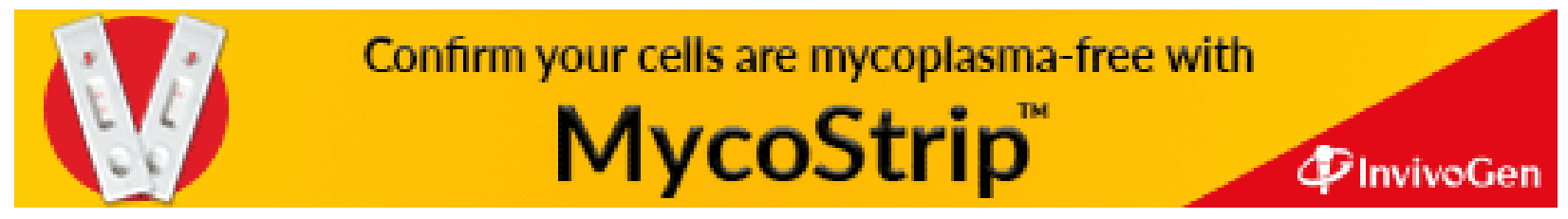

